\title{
DIÁRIO DE ITINERÂNCIA, RECURSO PARA FORMAÇÃO E AVALIAÇÃO DE ESTUDANTES UNIVERSITÁRIOS
}

LAURINDA RAMALHO DE ALMEIDA

\section{RESUMO}

Este artigo tem o objetivo de relatar a experiência da utilização do diário de itinerância, de René Barbier (2007) em dois cursos de pós-graduação stricto sensu. 0 termo, cunhado pelo autor, é entendido como "bloco de apontamentos, no qual cada um anota o que sente, o que pensa, o que medita, o que poetiza, o que retém de uma teoria, de uma conversa, o que constrói para dar sentido à vida". Barbier o propõe como técnica de pesquisa-ação, mas nos cursos foi empregado como recurso para formação e avaliação. Do primeiro curso são apresentados exemplos de diários elaborados e do segundo, depoimentos de alunos que os elaboraram e socializaram. Dentre as apreciações dos alunos quanto ao seu trabalho com os diários de itinerância destacam-se: registrar, nos diários, o que os afetou em sua trajetória escolar e profissional, proporcionou maior intimidade com o texto lido e discutido, e levou-os a reconhecer seu valor como profissional; além disso, forneceu elementos para autoconhecimento, tanto para o autor como para os que participaram da socialização.

PALAVRAS-CHAVE: AVALIAÇÃO DA APRENDIZAGEM •

FORMAÇÃO PROFISSIONAL・ ESTUDANTES • DIÁRIO DE

ITINERÂNCIA • PÓS-GRADUAÇÃO. 


\section{RESUMEN}

Este artículo tiene el objetivo de relatar la experiencia de la utilización del diario de itinerancia, de René Barbier (2007) en dos cursos de posgrado stricto sensu. El término, acuñado por el autor, se entiende como "bloc de apuntes, en el que cada uno anota lo que siente, lo que piensa, lo que medita, lo que poetiza, lo que retiene de una teoría, de una conversación, lo que construye para darle sentido a la vida". Barbier lo propone como una técnica de investigación-acción, pero en los cursos fue utilizado como un recurso de formación y evaluación. Del primer curso se presentan ejemplos de diarios hechos y del segundo, declaraciones de alumnos que los han elaborado y socializado. De las apreciaciones de los estudiantes sobre su trabajo con los diarios de itinerancia se destacan: registrar en el diario lo que los afectó en su trayectoria escolar y profesional, hecho que proporcionó mayor intimidad con el texto leído y discutido, y les permitió reconocer su valor como profesionales, además, proveyó elementos para el autoconocimiento, tanto para el autor como para los que participaron de la socialización.

PALABRAS CLAVE: EVALUACIÓN DEL APRENDIZAJE •

FORMACIÓN PROFESIONAL • ESTUDIANTES • DIARIO DE

ITINERANCIA • POSGRADO.

\section{ABSTRACT}

This article aims to present an experiment using the itinerancy diary in two Graduate Programs, as discussed by René Barbier (2007). The term, coined by the author, is understood as a "notepad in which each one jots down what he feels, what he thinks, what he meditates about, what he makes poetry about, what he aprehends from a theory, from a conversation, what he builds to give meaning to life". Barbier proposes this as a technique for action-research, but in these courses, we used it as a technique for training and assessment. From the first course, we provide examples of the diaries that were elaborated, and from the second course, we present testimonies from the students who elaborated and socialized their diaries. Among these students' declarations of their work with these itinerancy diaries, we highlight: to register in the diary what made an impact on their paths as students and as professionals, gave them greater intimacy with the articles that were read and discussed, and made them aware of their value as professionals. In addition, it gave them elements for self-knowledge, not only to those who wrote the diary, but also to those who listened to it.

KEYWORDS: LEARNING ASSESSMENT • PROFESSIONAL

TRAINING • ITINERANCY DIARY • GRADUATE STUDENTS. 


\section{INTRODUÇÃO}

O objetivo deste artigo é relatar a experiência da utilização do diário de itinerância, proposto por René Barbier (2007), em dois cursos de pós-graduação stricto sensu.

Tomo aqui experiência na acepção atribuída por Larrosa (2002, p. 21):

\footnotetext{
A experiência é o que nos passa, o que nos acontece, o que nos toca. Não o que se passa, não o que acontece, ou o que toca. A cada dia se passam muitas coisas, porém, ao mesmo tempo, quase nada nos acontece. Dir-se-ia que tudo o que se passa está organizado para que nada nos aconteça. Walter Benjamin, em um texto célebre, já observava a pobreza de experiência que caracteriza o nosso mundo. Nunca se passaram tantas coisas, mas a experiência é cada vez mais rara.
}

E, como Larrosa (2002), creio que é na relação entre o conhecimento e a vida humana que se constitui a experiência, e creio também no poder das palavras, no que podemos fazer com as palavras, e o que as palavras podem fazer conosco. Por isso, os apontamentos que seguem têm a ver com a relação entre conhecimentos 
e vida concreta, e com o fato de as palavras, escritas e faladas, terem força, quando se transformam em sentidos.

A experiência entre professora e alunos tocou-nos; ela, que propôs o diário de itinerância como recurso para formação e avaliação, e eles, que o escreveram e socializaram.

\section{O DIÁRIO DE ITINERÂNCIA}

Minha primeira aproximação com o diário de itinerância deuse em 2007, quando me preparava para ministrar o curso de pós-graduação stricto sensu sobre "A dimensão afetiva na perspectiva de Henri Wallon".

O curso estava parcialmente planejado, os textos escolhidos com cuidado. Entendo que afetividade já se expressa no planejamento: escolha de escritos que podem atingir o objetivo proposto, e que me afetam, pensando no quanto vão afetar meus alunos. Alguns, do próprio autor, capítulos de Psicologia e Educação da Infância (WALLon, 1975) e de A evolução psicológica da criança (Wallon, 2007); o Plano Langevin-Wallon (Merani, 1969); Retrato de Henri Wallon, escrito por René Zazzo (1978), discípulo e colaborador. Por entender, como Rollo May (apud Leite, 2002) que a literatura por vezes se presta melhor ao estudo da Psicologia do que compêndios da própria área, selecionei também Carta ao Pai, de Franz Kafka (1990) e alguns dos "pequenos momentos" de Eduardo Galeano em 0 livro dos abraços (2002). Também incluí um texto meu: 0 coordenador pedagógico e a questão do cuidar (ALmeidA, 2006).

Queria que meus alunos aproveitassem o curso, estudassem, discutissem. Mas bastava o meu querer para que os alunos quisessem? Se não, como envolvê-los? O fato de ser uma disciplina optativa já era um indicador de interesse. Mas eu queria mais: que o curso os fizesse perceber que poderiam chegar ao conhecimento com rigor e com leveza; perceber que se o binômio afetividade-aprendizagem é bem resolvido, promove uma aprendizagem pervagante, que perpassa o aluno por inteiro: afetividade, cognição, movimento.

Quais atividades, então, para envolver o aluno concreto, integral, presente no curso, imerso em inúmeras outras atividades cotidianas de trabalho, família e outras? E um problema 
igualmente sério: como avaliá-lo em um curso que se propunha a discutir dimensão afetiva?

Lembrei-me, então, do diário de itinerância de René Barbier (2007, p. 133), proposto como técnica de pesquisa para desenvolver pesquisa-ação: "bloco de apontamentos no qual cada um mostra o que sente, o que pensa, o que medita, o que poetiza, o que retém de uma teoria, de uma conversa, o que constrói para dar sentido à sua vida". Barbier argumenta que o diário de itinerância comporta o caráter de intimidade ao expressar reações em relação ao mundo circundante, como o fazem os diários íntimos, mas tem a característica de ser publicável, ou pelo menos, difundido no todo ou em partes. A volta aos fatos já passados, aos sonhos secretos, enfim, aos pensamentos e sentimentos que marcaram o itinerário percorrido por uma existência concreta, situada, é a sua característica.

Embora apresentado por Barbier como técnica de pesquisa, pareceu-me um bom instrumento para formação e avaliação de alunos. Com uma vantagem: ajudá-los a desenvolver sua habilidade de escrita. Resolvi, então, empregá-la como instrumento de formação e avaliação (necessidade minha) e de estudo (necessidade dos alunos)

O diário de itinerância compõe-se, concretamente, de três fases:

- diário rascunho: "ele escreve tudo o que ele tem vontade de anotar no fervilhar da ação ou na serenidade da contemplação. Nesse momento, ele não procura efeitos de estilo. Empenha-se em registrar o que lhe parece importante na sua vida ligada à de outrem. Pode ter seu próprio código de escrita abreviada”. (BARBIER, 2007, P. 138)

- diário elaborado: constituído a partir do diário rascunho. Outras reflexões, outros fatos podem ser acrescentados para compor o texto a ser comunicado a outro. "Eu me obrigo a apresentar-lhe um texto trabalhado, respeitando assim sua qualidade de leitor. Empenho-me em escrever com simplicidade o que pertence ao domínio da complexidade, sem renegar, entretanto, minha cultura, minhas experiências, minhas áreas de conhecimento ou minhas expressões afetivas. [...]" (BARBIER, 2007, P. 139-140)

- diário comentado ou socializado: "Durante toda a fase do diário elaborado eu estou em contato imaginário com 
um leitor virtual. Eu escrevo para mim e para outrem. Eu sou, por excelência, um ser social. [...] Eu o ofereço para leitura ou exponho o fragmento (ou a totalidade) do diário elaborado para o leitor ou o grupo de leitores que tenho diante de mim". (BARBIER, 2007, P. 142)

Afirma, ainda, Barbier:

\begin{abstract}
Nada impede evidentemente que o diário de itinerância se socialize ainda mais e se torne um diário de itinerância coletivo, isto é, redigido por um grupo ou subgrupo. Nesse caso, o diário de itinerância coletivo representa o caderno de inteligência do grupo em direção à realização de seu objetivo. (2007, p. 143)
\end{abstract}

Apresentado o diário de itinerância como proposta de estudo e avaliação do curso, a concordância em trabalhar como ele foi unânime.

Ficou acordado que a cada quarta-feira (dia da aula) cada um elaboraria, em casa, seu diário, um diário do vivido: as relações do texto lido e discutido em classe com sua trajetória profissional e/ou de aluno: sucessos, insucessos, alegrias, tristezas; que a cada quatro semanas seria feita a socialização dos diários; que os três últimos encontros do semestre seriam reservados para a elaboração, em grupo, de trabalhos escritos a partir dos diários. Acordado, também, que o critério para a avaliação seria a adequação entre o texto lido e discutido com os fatos rememorados da trajetória pessoal. ${ }^{1}$

Selecionei trechos de alguns diários para exemplificar os apontamentos que seguem.

- Escrever na primeira pessoa não é fácil... ouvir os outros ajuda.

Os primeiros diários de alguns alunos se apresentaram mais como fichamento de textos, atividade à qual estavam acostumados. Chegaram a comentar que se percebiam "engessados" na hora da escrita. Mas ouvir os outros relatarem o seu, na socialização programada, despertou-lhes o interesse pela atividade, e levou-os a maior esforço e satisfação para a elaboração do diário.

Francisco, professor universitário, chegou a solicitar a proposta de outro tipo de trabalho para ser avaliado. Mas

1 A experiência da

utilização dos diários de itinerância nesse curso, com autorização dos alunos, foi apresentada como comunicação no Congresso Nacional das Licenciaturas, Mackenzie, 
mudou seu olhar a partir da segunda socialização e fez questão de explicitá-lo.

Na aula do dia 03 de maio, quando lemos alguns diários de itinerância do grupo, ficou acordado que não precisaríamos enfocar este encontro em nosso diário, e que seria melhor colocarmos nossas tarefas atrasadas em dia.

Porém, senti a necessidade de escrever minhas impressões sobre a aula, principalmente quanto ao potencial deste instrumento em um grupo e o quanto a reflexão que este instrumento propicia e mexe com nossos sentimentos, nos fazendo revisitar nossa trajetória pessoal e/ou profissional e as representações que fomos incorporando em nosso caminhar.

Os textos lidos revelaram uma riqueza existente na multiplicidade de olhares que uma mesma leitura pode desencadear, pois, de acordo com as vivências e experiências de cada um, o foco vai sendo direcionado, nos possibilitando, por um lado, a pensar no nosso próprio processo de aprendizagem e, por outro, a aprender com os colegas, por meio de seus olhares distintos, nos possibilitando a "olhar com seus olhos", a vislumbrar coisas que até então não faziam parte de nossas preocupações ou então ainda nos eram desconhecidas.

Este descortinar que a leitura dos colegas proporcionou foi muito rico, como a produção da Zildene, por exemplo, que me fez visitar sua terra e me aproximar ainda mais de sua verdade, de seu sonho, do sentido de estar entre nós, ou seja, de sua paixão em ser professora alfabetizadora. Mas, em ser professora alfabetizadora não em qualquer lugar, seu olhar se volta para sua terra, local onde construiu sua história. Essa aproximação só foi possível por termos acolhido a proposta da professora de utilizar o diário de itinerância como referência para os nossos estudos.

Depois desta aula, o diário de itinerância para mim passou a ser algo a mais que um simples instrumento didático, ele se revelou como um procedimento rico, que transcende apenas o aspecto cognitivo, possibilitando fazer emergir toda a riqueza que mobiliza o ser humano na busca de conhecimento, que vem carregado de paixões e necessidades que, com certe$z a$, foi o que nos mobilizou a procurar este espaço de estudo, aspectos que nem sempre ficam claros sem serem provocados para poderem se manifestar e que os escritos compartilhados mostraram possibilitar. 
É interessante perceber que os diários de itinerância proporcionam manifestações em várias dimensões, que se fazem presentes de acordo com o texto estudado, podendo ser possivel abordá-lo ou estudá-lo em vários aspectos, entre os quais, os que mais me chamaram a atenção foram os seguintes: [...]

Também é interessante notar que as dimensões descritas se fazem presentes de acordo com o texto estudado, podendo se manifestar uma delas ou várias, dependendo da natureza do texto e/ou das reflexões que as idéias do autor instigaram.

Aqui encerro esta reflexão, que, com certeza, irá influenciar a produção das próximas páginas de meu diário, pois uma nova significação irá orientar minha ação no desenvolvimento desta atividade.

- A expressão da afetividade nos diários

A escrita da maioria dos diários foi permeada de sentimentos de variadas tonalidades, relacionados aos textos lidos. Exemplifico com dois diários de Zildene, professora alfabetizadora, que desde o início se relacionou prazerosamente com seus diários.

Diário de itinerância de 28 de março de 2007

"Da minha aldeia vejo quanto da terra se pode ver do universo...

Por isso a minha aldeia é tão grande como outra terra qualquer,

Porque eu sou do tamanho do que vejo

E não do tamanho da minha altura..."

(Fernando Pessoa - Poesia completa de Alberto Caeiro)

A busca de uma compreensão desenfreada de minhas necessidades primordiais, enquanto alfabetizadora, me levam de um extremo a outro nas leituras e nas recordações. Continuar apresentando Fernando Pessoa no início da minha escrita me remete ao entendimento de que embora minha "aldeia", e assim me refiro a minha cidade, seja pequena, foi lá que vislumbrei a possibilidade de buscar outras abrangências no que eu ainda poderia aprender, outros olhares, a busca por imagens que estavam além da Chapada do Araripe, uma chapada que é verde o ano inteiro e que forma um paredão circundando a cidade do Crato/CE.

Foi nesse espaço geográfico, aparentemente restrito, que me formei professora alfabetizadora, em vários espaços formativos e de lá também aprendi a lapidar meu olhar, minha forma de ler, 
de escrever e de me deparar com situações de conflitos cognitivos até chegar aonde cheguei.

Quando iniciei a leitura do texto: "As etapas da sociabilidade na criança”, de Henri Wallon, percebi ou pelo menos me dei conta mais nitidamente que o meu lugar, minha "aldeia" também me impossibilitava algumas chaves que me incapacitavam ir além da tão esperada utopia, enquanto um sonho possivel, porque muitas coisas eu ainda não sabia e mesmo assim continuava sendo professora de crianças.

Tantas experiências foram partilhadas em sala de aula como se fosse um tatear para acertar uma forma de ensinar crianças a ler e escrever sem ter medo das letras e assim continuei a leitura do texto, sendo tomada por questionamentos, por uma sensação que errei muito em sala de aula pelo desconhecimento de algumas teorias, mas que também acertei em busca de um novo caminho. Fiquei com uma sensação de preenchimento e ao mesmo tempo de esvaziamento nas novas aprendizagens que me chegavam, porque aо mesmo tempo em que eu ia adquirindo um olhar diferenciado para a sociabilidade da criança, novos questionamentos emergiam e assim fui seguindo trecho por trecho da leitura proposta com toda atenção.

[...]

E assim minhas compreensões foram sendo ressignificadas e o que ora parecia o paredão verde da Chapada do Araripe cobrindo a visão do meu espaço aparentemente restrito, parecia também um descortinar da compreensão do desenvolvimento da criança com novas chaves, novas saídas, outros tantos entendimentos e um desejo enorme de levar o que aprendi para aqueles que ainda não conseguiram sair da "aldeia".

Diário de itinerância de 18 de abril de 2007

“Contar é muito dificultoso. Não pelos anos que já se passaram. Mas pela astúcia que têm certas coisas passadas de fazer balancê, de se remexerem dos lugares".

João Guimarães Rosa

O texto sobre o "coordenador pedagógico e as questões do cuidar", escrito pela professora Laurinda Ramalho, me levou para um lugar distante, com pessoas que não tenho contato pelo menos há uns quinze anos. Senti um misto de saudade e ao 
mesmo tempo uma alegria indizivel e mais ainda uma recordação tão acesa que mais parecia ontem ou hoje e assim como diz Guimarães Rosa contar é algo muito dificultoso porque as informações acabam se mexendo dos seus lugares e nos fazendo sentir saudade.

$[\ldots]$

Durante a discussão em sala de aula, surgiu a fala de uma das colegas do curso relativa à necessidade de cuidar das diferentes passagens, aqui ela se referia aos alunos que passavam da quarta para a quinta série do ensino fundamental e pensei logo em seguida; será que esse cuidar seria apenas de crianças e adolescentes ou também poderia ser o cuidar do adulto?

$[\ldots]$

Embora não deseje me sentir dessa forma, estou me sentindo um tanto perdida nesta cidade, é uma sensação dolorida, é como se "todos" tivessem ido embora e eu tivesse ficado sem "cuidados", é uma sensação contraditória, pois ao mesmo tempo em que me sinto bem cursando esta disciplina, a sair da sala de aula, sinto como se apenas o diário de itinerância me fizesse companhia para repensar os textos e trazer lembranças que fazem "link" com o estudado até esperar pela semana que vem para mais um dia de aula.

Sinto como se ao escrever cada trechinho deste diário de itinerância eu estivesse cuidando um pouco mais de mim, do silêncio que teima em ser bem maior nesse momento, de cuidar da minha compreensão dos textos, de olhar para o doutorado de uma outra posição de quem ainda tem muito a aprender e que o processo de aprendizagem nem sempre é algo prazeroso, é também um processo dolorido e em especial tenho cuidado de todo o percurso para a elaboração da tese.

- O grupo é importante

Viviane, analista pedagógica, apresenta suas considerações depois de uma socialização dos diários. Dentre outros pontos, destaca a importância de participar das discussões, e não ficar só na leitura do texto.

[...] Outro ponto foi perceber a importância de estar presente nas discussões propostas pela professora para o nosso estudo. Escrever um diário do vivido não é a mesma situação de escrever um diário de um texto lido. A aula traz várias 
representações de diferentes pessoas, no diálogo podemos expor nossos entendimentos e discutir ideias com o outro. 0 quanto é importante para um aprendizado essa relação com o outro. Ao deparar com a minha escrita do primeiro texto, vi o quanto perdi não estando com o grupo, minhas representações permaneceram intocáveis, não havia outro para ter um contraponto. Essa vivência é insubstituível, como diz Madalena Freire: um autodidata tem uma educação empobrecida, pois não discute suas ideias com ninguém.

- O diário de itinerância como recurso para comunicar-se com o professor

Nem sempre o aluno encontra espaço, na sala, para revelar certas situações, e, então, o diário é um recurso para isso. O diário de Tadeu reflete bem esse aspecto.

Não vá estranhar! Quando discutimos o texto "O coordenador pedagógico e a questão do cuidar", eu estava preocupado em elaborar um discurso porque havia sido convidado para ser patrono de uma turma de Psicologia [...]. Eu formulei o discurso durante sua aula, não sei se você percebeu, mas eu não parava de anotar coisas, até quando ninguém falava.

- Para encerrar este primeiro bloco

O curso do $1^{\circ}$ Semestre de 2007 foi marcante, para mim e para os alunos. A utilização do diário de itinerância provocou a expressão da relação teoria-prática, de dúvidas, de rememorações, de acertos de contas com alguns vividos enfim, provocou a integração cognitiva-afetiva muito favorável à aprendizagem dos textos, alguns de difícil entendimento.

Alcancei, com seu emprego, o que pretendia: mostrar aos alunos que é possível chegar ao conhecimento com rigor e com leveza (embora às vezes seja um processo dolorido), mostrar que afetividade-cognição-movimento, as três dimensões da teoria walloniana que integram a pessoa, estão sempre juntas, presentes na sala de aula, embora com preponderâncias diferentes, em qualquer nível de ensino.

Os trabalhos que os grupos apresentaram, elaborados nos três últimos encontros, foram de excelente qualidade, apresentando rigor científico e, alguns, uma saborosa relação com clássicos da literatura. Além disso, três alunos relataram 
a utilização de diários de itinerância nos cursos de licenciatura que ministravam, com resultados muito bons, para os alunos e para eles.

\section{AMPLIANDO A UTILIZAÇÃO DOS DIÁRIOS DE ITINERÂNCIA}

Embora tenha empregado a proposta de Barbier (2007) como recurso de formação e avaliação em outras situações, detenhome em curso realizado no $1^{\circ}$ semestre de 2011, na disciplina obrigatória "Psicologia da Educação II", que se propunha a discutir alguns temas relevantes da educação brasileira, tais como: educação, escola e sociedade; escola, família e sociedade; afetividade e constituição do professor e do aluno; formação e desenvolvimento profissional dos professores e produção do sucesso escolar, procurando articular, tanto quanto possível, os textos indicados com o cotidiano da escola.

Os textos discutidos encontram-se relacionados nas referências bibliográficas, com exceção dos registrados na discussão do primeiro curso.

Três meses após o término do curso (setembro/2011), apresentei aos alunos duas questões: "O que significou ter escrito os diários de itinerância? E o que sentiu quando os socializou? Por favor, não seja econômico(a) nas respostas”. Todos responderam, por escrito, e autorizaram-me a utilizar seus diários e respostas em comunicações e artigos, e com identificação. ${ }^{2}$ Cumpre observar que os depoimentos foram dados pelos alunos em situação normal de sala de aula, por autorização da professora do curso desenvolvido no semestre.

Neste artigo, utilizo apenas as respostas, em função do espaço limitado. Somente um trecho do diário comparece, porque retrata muito bem como Dayse, coordenadora pedagógica, 2 Agradeço a todos, e particularmente àqueles de quem utilizei as respostas para os apontamentos que sequem: Beatriz Gouveia, Dayse Gonçalves, Henrique M. de Castro, Judivania de Andrade Dias, Maria Luiza G. de Castro, Priscilla Andrea Glaser, Sandra Puliezi, Thais P. A. Soares e Vanessa Cristina da Silva. compreendeu a elaboração do diário, tanto o rascunho, como o elaborado.

Creio que podemos chamar os registros de aula de primeiro rascunho. É o espaço onde registramos o modo como processamos as informações que circulam em sala a partir da fala do professor e dos colegas a propósito dos assuntos postos em pauta. Mas há também pequenos registros que antecedem esse primeiro rascunho, e que acontecem no 
momento em que realizamos as leituras propostas. Às vezes são palavras ou pequenas frases que anotamos às margens dos textos. Neste caso, já foram várias sessões de leitura seguidas de discussões. Foram textos valiosos, artigos apresentados com o cuidado de garantir um encadeamento que favorece não só a construção de sentidos de cada um deles, mas também a compreensão da problemática educacional do nosso país. [...]

Fiquei pensando um bom tempo como iniciar este diário, já que por ser também um espaço para refletir sobre o próprio desenvolvimento profissional cabem tantas coisas, tantas experiências. O que escolher? Onde vieram à minha mente muitas perguntas. Perguntas que os referidos textos de Canário me ajudam, neste momento, a responder. [...]

\section{O QUE REVELARAM OS DEPOIMENTOS SOBRE O DIÁRIO DE ITINERÂNCIA}

Uma experiência nova e boa, pelo acolhimento do grupo, Maria Luiza, orientadora educacional, fala da falta de tempo para compartilhar suas vivências e da importância do acolhimento do grupo.

Ter escrito os diários de itinerância foi uma experiência nova em minha vida pessoal e profissional, uma vez que foi a primeira oportunidade que tive de relacionar aspectos pessoais-afetivos com os textos solicitados para leitura. Foi excelente traçar paralelos, recordar vivências e correlacioná-los com minha experiência como Orientadora Educacional. São tantas as vivências e tão pouco tempo para partiThá-las... Acredito que o reconhecimento e o acolhimento que o grupo proporcionou tenha sido fundamental para continuarmos. 0 olhar atento e a escuta respeitosa dos colegas e da professora serão pontos a serem recordados para sempre em minha vida.

Sandra, professora alfabetizadora, revela sua estranheza com a atividade proposta, e de como se esforçou para desenvolvê-la.

Escrever os diários foi, no início, uma sensação muito estranha. De que maneira eu poderia trazer minhas vivências e, juntamente com a leitura da semana, transformar isso em um texto? A princípio ficava presa na leitura, não conseguia explorar muito minhas lembranças. 
Aos poucos, escutando os diários dos colegas, que muitas vezes eram emocionantes, fui me soltando e começando a aparecer mais no meu diário. Mesmo assim, ainda não achava que estava bom o suficiente como os dos meus colegas. [...] Quando passamos a ouvir os relatos dos outros, queremos contar o nosso também. Eu sabia que o meu diário não estava tão bom quanto os de alguns colegas, mas mesmo assim queria contar o pouco que eu tinha para contar.

\section{- O prazer da autoria}

Vanessa, socioeducadora, expõe o prazer de falar na primeira pessoa:

O diário se apresentava como uma narrativa nossa, como escritos que contassem a nossa viagem, trazendo aspectos profissionais e emocionais de uma trajetória de vida. [...] Escrever na primeira pessoa foi tão prazeroso, sempre tentava omitir o "eu", mas desta vez era esse pronome em primeira pessoa que regia a história [...] No fim de todo o processo socializávamos os nossos textos com os colegas; é impressionante como uma simples aula despertava tantos sentimentos: timidez, medo, euforia, saudade, e como lidar com eles. Quando olho para trás não acredito que produzimos tanto. Muitos textos guardarei com carinho lembrando do processo que o constituiu.

Dayse, coordenadora pedagógica, fala ainda do reconhecimento do próprio valor:

A experiência de ter produzido os diários foi muito significativa para mim. Dava-me a possibilidade de ressignificar, por um lado, minha trajetória como aluna e como professora, e, por outro, de relacionar autores e leituras com as minhas próprias experiências. Foi também uma experiência de liberdade intelectual, se é que posso chamar assim. Era possivel fazer escolhas numa atmosfera de aceitação e respeito pela diversidade de trajetórias presentes no grupo. [...] A par disso, posso afirmar, ainda, que a tarefa de elaborá-los foi também muito prazerosa porque nos permitia reconhecer nosso próprio valor. E quanta emoção também nos momentos em que compartilhávamos com nossos pares.

- A superação de desafios

Judivânia, diretora de escola, relata a dificuldade em começar a escrita dos diários e a alegria por superá-la. 
Escrever o diário de itinerância foi muito difícil, a princípio, para mim. A experiência foi como "exorcizar" meus monstros, "construídos" ao longo da minha vida escolar. [...]

Enfrentei uma luta enorme na busca pela superação do medo da exposição, do julgamento, da vergonha por ter que "expurgar" sentimentos que fizeram parte de minha história estudantil. [...] Assim, tomei coragem numa aula e falei, ou melhor, "socializei". A partir daquele momento, produzir o Diário passou a ser uma experiência impar: uma viagem de conhecimento, perpassando por reflexões, lembranças, elos entre passado e presente e projeção para o futuro.

Ao final estava muito feliz com o "produto". Creio que não se tratou de nenhuma obra de arte, mas acabou se tornando uma grande realização para mim.

- O cuidado com a escrita e a importância de sua regularidade Thaís, professora do ensino fundamental, revela seu respeito pelo outro que vai ouvir seu diário:

Socializar os diários trouxe um cuidado com a escrita, pois precisávamos levar em consideração o destinatário e assim tínhamos que escrever de forma clara. Além disso, partilhávamos diferentes linguagens e sentidos, a partir da leitura de um mesmo texto. Os diários retratam a diversidade de uma turma e o quanto o conhecimento construído é pessoal.

Beatriz, formadora de professores, registra sua preocupação com a regularidade da escrita.

Para cada diário houve uma provocação para aprofundarmos em algum ponto de observação, em um foco. Este aspecto foi fundamental para centrarmos nosso olhar e nossa reflexão e ganhar mais aprofundamento.

Escrever é um espaço importante e privilegiado de reflexão. No entanto, para que a escrita se torne mais fluida, mais autônoma, mais desenvolta, precisamos que ela seja regular em nossas vidas, que tenha constância em nosso trabalho. A regularidade torna a escrita cada vez mais intima, mais precisa, as palavras vão tornando-se, gradativamente, mais planejadas, mais certeiras. E nós, autoras, vamos nos entendendo melhor com os movimentos que animam cada um de nossos textos. 
- A socialização: momento de formação, de alegrias, de apreensões

Beatriz continua sua reflexão com os diários:

Os diários me ajudaram com a regularidade da escrita, com a capacidade de reflexão, com a possibilidade de me sentir mais autora de meus próprios textos.

A proposta de socializar os diários criou um outro momento de formação, diferente do ato da escrita. Ao comunicar nossas ideias nos damos conta de nossas reflexões, de nossas fragilidades, de que o texto poderia ser melhor escrito, de contrapontos com as ideias dos colegas, de novas relações que poderiam ser estabelecidas. E ao ouvir os diários dos colegas temos a confirmação de que o olhar dos outros melhora o nosso. Viva a cultura colaborativa da aprendizagem!

Priscilla, psicóloga, revela receios e alegrias:

Quanto à socialização dos meus diários, essa é uma parte que ora me gerou "frio na barriga" (vão entender o que eu escrevi? O que vão achar?), ora me deu muita vontade de compartilhar as minhas burilações, como se fossem ricas descobertas a serem divididas com outros.

Escutar os diários foi sempre uma dádiva! Cada história de vida, cada articulação de experiência prática com a teoria, cada novo pensamento, cada nova poesia, enfim, foram muitas surpresas e riquezas tecidas ali naquela troca.

- Uma forma nova de avaliar

Priscilla revela agora como percebeu os diários como modalidade de avaliação.

A experiência de escrever os diários de itinerância foi única e inédita! Desde o início achei essa forma de avaliação inovadora e surpreendentemente boa! 0 que a torna tão única?!

Um aspecto é que não é uma avaliação meramente proforma, algo para somente dar uma nota, e acabou! Não é uma avaliação que está pautada em decorar, memorizar conceitos e ideias. É um método de avaliação ousado e muito ético, por levar absolutamente em conta a singularidade de cada aluno, uma vez que cada um, ao escrever o diário, conta da SUA PRÓPRIA experiência de aprendizagem dos textos! Uma experiência que envolve a apropriação e compreensão dos textos de forma única 
para cada um. Experiência que articula o leitor dos novos textos com sua experiência de vida, valores, emoções!

Outro aspecto extremamente relevante de constar aqui é que, antes de ser uma avaliação a ser entregue para a professora, é este um método de AUTOAVALIAÇÃO! Sou eu, como aluna, que posso me debruçar sobre o que eu li e sobre o que foi discutido em aula e posso refletir sobre o que fica para mim de toda essa aprendizagem.

Henrique, recém-graduado em psicologia, expõe seus sentimentos:

Tive sentimentos ambíguos nas duas fases. Alguns diários foram fáceis de serem feitos, pois eram temas que mais me interessavam ou que teria mais que falar. Outros acabaram sendo mais mecânicos, pela obrigação. Mas de qualquer forma, foi ótimo. Muito melhor que outras formas de avaliação. [...]

Digo que gostei da dinâmica e que me senti bastante à vontade para usar como ferramenta quando estiver cumprindo as vezes de professor.

Sandra registra, com mágoa, que os diários significaram mais que avaliação.

Houve uma vez [...] em que todos iam socializar seus últimos diários. Era nossa última oportunidade para isso. A professora orientou para que as pessoas escolhessem um deles para socialização. Mas as pessoas se empolgavam (o que é perfeitamente compreensivel!!!) e acabavam lendo mais de um. O que aconteceu foi que eu e mais duas colegas, que estávamos no fim da roda, não tivemos a oportunidade de ler. Devo confessar que fiquei frustrada. E minhas colegas também. Por que isso mexeu comigo?

Naquele momento percebi que os diários significavam mais para nós do que uma avaliação. Eles significavam dividir com os companheiros de sala um pouco de nossas lembranças. E isso é bom.

- Para encerrar este segundo bloco

A qualidade dos diários apresentados no transcorrer do curso foi surpreendente. Os diários traziam, além do confronto do texto discutido com a trajetória pessoal, relações com outros autores, com a literatura, com a pintura. Empolgados com a produção, alguns alunos propuseram a elaboração de um livro: 
cada um escolheria um de seus diários que se tornaria um dos capítulos do livro. Não fui suficientemente hábil para operacionalizar a ideia e a proposta não se concretizou.

\section{À GUISA DE CONCLUSÃO}

Retomo, aqui, constatações que a utilização do diário de itinerância, como recurso de formação e avaliação, possibilitou. A primeira delas, da qual decorrem as demais, é que, para trabalhar adequadamente o conhecimento, é preciso levar em conta a integração cognição-afetividade.

Seguem outras, entre tantas possíveis:

- registrar, nos diários, o que afetou (“tocou”) a pessoa em determinado ponto de sua trajetória de vida, proporcionou maior intimidade com o texto lido e discutido;

- recordar, para relacionar com os textos, fatos da vida profissional e/ou pessoal, permitiu ao autor do diário reconhecer seu próprio valor;

- socializar reflexões feitas, permitiu a ampliação do autoconhecimento, tanto para o autor, como para os ouvintes;

- escrever na primeira pessoa, reconhecer-se autor, ser ouvido com respeito, estimulou para novas escritas.

E, finalmente, a qualidade das relações interpessoais é fundamental para que os objetivos de uma proposta de formação e avaliação do tipo diários de itinerância sejam atingidos. Um olhar atento, um ouvir ativo, um falar autêntico são recursos para a melhoria dessa qualidade.

Quando a proposta de formação faz sentido para o formador e o formando, a resposta vem na forma de uma aprendizagem significativa, que passa pela pessoa inteira, envolvendo o sentir, o pensar e o agir, e abre caminho para autonomia e autoria.

\section{REFERÊNCIAS BIBLIOGRÁFICAS}

AGUIAR, Wanda Maria Junqueira; BAPTISTA, Marisa T. A Transformação do professor como elemento mobilizador de mudança na realidade escolar. Psicologia da Educação, São Paulo, n.16, p. 83-102, $1^{\circ}$ semestre 2003. 
ALMEIDA, Laurinda R. Ensino noturno: memórias de uma experiência. São Paulo: Loyola, 2010.

O Coordenador pedagógico e a questão do cuidar. In: ALMEIDA, Laurinda R.; PLACCO, Vera M. N. S. (Org.) O Coordenador pedagógico e questões da contemporaneidade. São Paulo: Loyola, 2006.

ALMEIDA, Laurinda Ramalho; PLACCO, Vera M. N. S. (Org.) O Coordenador pedagógico e questões da contemporaneidade. São Paulo: Loyola, 2007.

BARBIER, René. A Pesquisa-ação. Brasília: Liberlivro, 2007.

CANÁRIO, Rui. A Escola, o lugar onde os professores aprendem. Psicologia da Educação, São Paulo, n. 6, p. 9-27, $1^{\circ}$ semestre 1998.

Formação e desenvolvimento profissional dos professores. Livro da conferência de desenvolvimento profissional de professores para a qualidade e para equidade da aprendizagem ao longo da vida. Lisboa: Universidade de Lisboa, 2007.

CASASSUS, Juan. A Escola e a desigualdade. Brasília: Plano, 2002.

CODO, Wanderley (Org.). Educação: carinho e trabalho. Petrópolis: Vozes; Brasília: Confederação Nacional dos Trabalhadores em Educação, 1999.

GALEANO, Eduardo. O Livro dos abraços. Porto Alegre: L\&PM, 2002.

GATTI, Bernardete A. Formação de professores: condições e problemas atuais. Revista Brasileira de Formação de Professores, v. 1, n. 1, p. 90-102, maio 2009.

Pós-modernidade, educação e pesquisa: confrontos e dilemas no início de um novo século. Psicologia da Educação, São Paulo, n. 20, p. 139-151, $1^{\circ}$ semestre 2005.

KAFKA, Franz. Carta ao Pai. São Paulo: Brasiliense, 1990.

LARROSA, Jorge B. Notas sobre a experiência e o saber da experiência. Revista Brasileira de Educação, n. 19, p. 20-28, jan./abr. 2002.

LEITE, Dante M. Psicologia e literatura. São Paulo: Unesp, 2002.

LEITE, Sérgio A. da Silva (Org.). Afetividade e práticas pedagógicas. São Paulo: Casa do Psicólogo, 2006.

MERANI, Alberto. Psicología y pedagogía: las ideas pedagógicas de Henri Wallon. México, DF: Grijalbo, 1969.

PLACCO, Vera M. N. S.; ALMEIDA, Laurinda Ramalho (Org.). O Coordenador pedagógico e os desafios da educação. São Paulo: Loyola, 2008.

RONCA, Vera de F. Caruso. Docência e admiração: da imitação à autonomia. São Paulo: Edsplan, 2007.

SEVERINO, Antonio Joaquim. O Projeto político pedagógico: a saída para a escola. Revista de Educação AEC, Brasília, v. 27, n. 107, p. 81-91, abr./jun. 1998.

SILVA, Graziela Lucchesi R. Psicologia educacional e arte literária: interlocuções para a compreensão dos laços familiares e escolares na atualidade. Psicologia da Educação, São Paulo, n. 24, p. 137-151, $1^{\circ}$ semestre, 2007. 
SZYMANSKI, Heloisa. A Família como lócus educacional: perspectivas para um trabalho psicoeducacional. Revista Brasileira de Estudos Pedagógicos, Brasília, v. 81, n. 197, p. 14-25, jan./abr. 2000.

WALLON, Henri. A Evolução psicológica da criança. São Paulo: Martins

Fontes, 2007

Psicologia e educação da infância. Lisboa: Estampa, 1975.

ZAZZO, René. Henri Wallon: psicologia e marxismo. Lisboa: Vega, 1978.

\section{LAURINDA RAMALHO DE ALMEIDA}

Doutora em Psicologia da Educação na

Pontifícia Universidade Católica de São Paulo - PUCSP

laurinda@pucsp.br

Recebido em: DEZEMBRO 2011

Aprovado para publicação em: JANEIRO 2012 